\title{
ANALYSIS OF MATERNAL MORTALITY IN A TERTIARY CARE CENTRE: A 5 YRS RETROSPECTIVE STUDY.
}

Shabana Sultan, Aruna Kumar, Divya Bhagchandani, Hena Dhingre

1. Assistant Professor. Department of Obstetrics \& Gynaecology, Gandhi Medical College, Bhopal.

2. Professor. Department of Obstetrics \& Gynaecology, Gandhi Medical College, Bhopal.

3. Resident. Department of Obstetrics \& Gynaecology, Gandhi Medical College, Bhopal.

4. Resident. Department of Obstetrics \& Gynaecology, Gandhi Medical College, Bhopal.

\section{CORRESPONDING AUTHOR:}

Dr. Shabana Sultan,

House no 1/115 OPD block,

Doctor's campus, Sultania Lady Hospital,

Bhopal- 462001. Madhya Pradesh.

E-mail: shaby_2k2@yahoo.com

Ph: 00919893192593

KEYWORDS: Maternal mortality ratio, Hypertensive disorder of pregnancy, EMoC emergency obstetric care

ABSTRACT: AIMS: This study aimed to study the determinants, common causes and possible prevention of maternal mortality. MATERIALS AND METHODS: Maternal mortalities in Department of Obstetrics and gynecology, Gandhi medical college, Sultania Zanana Hospital, Bhopal during 5 year period from Jan 2007- Dec 2011 were studied. The individual records of all maternal deaths occurring during the study period of 5 years were extracted from patient's case notes and hospital record registers. Total deliveries for the period were extracted from the delivery registers. RESULTS : In the year 2007-2011 total live births were 43,683 of which 338 mothers died giving cumulative maternal mortality ratio of 773.75 per 1,00,000 live births. Among 338 total maternal deaths, the maximum deaths were in the age group 20-30 years (88.16\%).The death rate of mothers from rural areas was higher $(65.68 \%)$.The highest number of maternal death occurred among multigravidae (46.74\%) . A total of $91.72 \%$ of maternal death occurred in unbooked patients. Most were referred patients (74.55\%). Most of them were illiterate (61.8\%).76.62\% patients died within 24 hours of admission.33.13\% women died in antenatal period while $64.49 \%$ died in postnatal period. Direct obstetric causes of death accounted for $76.03 \%$ of all maternal deaths. Among the direct causes $39.64 \%$ died due to hypertensive disorder of pregnancy, $18.93 \%$ due to hemorrhage. Indirect causes accounted for $23.96 \%$ in which anemia $(8.57 \%)$, malaria $(3.55 \%)$ hepatitis $(2.66 \%)$ were the leading causes. CONCLUSIONS: This study has shown higher maternal mortality due to being a tertiary care hospital based study where more complicated and referred cases are admitted. Most maternal deaths can be prevented by providing care at grass root level, linkage between primary, secondary and tertiary care, strengthening of referral services and instituting emergency obstetric services.

INTRODUCTION: According to World health organization: Maternal death is defined as 'Death of a woman while pregnant or within 42 days of termination of pregnancy, irrespective of the duration and site of the pregnancy, from any cause related to or aggravated by the pregnancy or its management, but not from accidental causes or incidental causes(ICD 10 REVISION) ${ }^{[1]}$ 
MATERNAL MORTALITY RATIO is number of maternal deaths during given time per 100,000 live births during the same period.

Estimates by UNFPA indicates that one in every four women in developing countries suffer from acute or chronic condition related to pregnancy and 5\% of pregnant women need surgery. A woman dies every 90 seconds from complications during pregnancy or childbirth. It has been estimated that $86 \%$ of maternal death cases occur in Asian and Sub-Saharan Africa, with India alone accounting for $25 \%$ of such deaths worldwide. Data on causes of maternal death reveal that more than $80 \%$ of such deaths are due to direct obstetric causes ${ }^{[2]}$

MMR was 540 in 1999. Currently it is 212/100,000 live births by SRS 2007-2009. [3] Desired figure in millennium development goal is $100 / 100,100$ live births. India is also committed to 8th millennium development goal set by United Nations and one of the goals is reduction in maternal mortality ratio by $3 / 4$ th by 2015 . [4]

Maternal death has serious implication on the family, the society and the nation. The average lifetime risk of a woman in a developing country dying from complications related to pregnancy or childbirth is more than 300 times greater than for a woman living in an industrialized country. The preventable and avoidable factors have been noted in $50-80 \%$ of maternal deaths and these can be reduced through actions that are effective and affordable in developing countries [5]. Maternal mortality ratio is a very sensitive index that reflects the quality of reproductive care provided to the pregnant woman. This study was conducted to know the determinants of maternal mortality, to assess maternal mortality ratio and to determine the causes of maternal mortality at a tertiary care centre so that corrective steps can be taken to reach the goal.

MATERIAL AND METHODS: A Retrospective study was carried out over a period of five years from Jan 2007 to Dec 2011 in the department of Obstetrics \& Gynecology, Sultania Zanana Hospital, GMC Bhopal, a tertiary care \& biggest referral centre of Bhopal. All the women who died were pregnant or within 42 days of termination of pregnancy, irrespective of duration or site of pregnancy or its management but not from accidental or incidental causes were included in the study. All maternal deaths occurring during study period were analyzed with parity, cause of death, time interval from admission to death and trimester of pregnancy at the time of death, mode of management given.. All the relevant data were collected from hospital records and registers. Total number of deliveries during study period was extracted from delivery register. MMR was calculated by total number of live births.

RESULTS: Total vaginal deliveries during the study period were 34,443 . Total caesarean deliveries were 11,333. Total live births during the study period were 43,683. Total 338 maternal deaths were found giving maternal mortality ratio of 773.75/100,000 live births.

Table I: - Maternal mortality in 5 years

\begin{tabular}{|l|c|c|c|}
\hline Year & Total live births & Maternal deaths & MMR \\
\hline 2007 & 8099 & 67 & 827 \\
\hline 2008 & 8674 & 63 & 726 \\
\hline 2009 & 9840 & 77 & 782 \\
\hline 2010 & 9695 & 76 & 783 \\
\hline 2011 & 7375 & 55 & 745 \\
\hline 5 yrs & 43683 & 338 & 773.5 \\
\hline
\end{tabular}


Table I shows maternal death distribution in the five years of study. The highest MMR of 827 was in the year 2007, with the lowest of 745 in the year 2011. So the average of the 5 year study period was 773.5 per 100,000 live births.

Table II: - Clinical and demographic features

\begin{tabular}{|l|l|l|}
\hline & NUMBER & PERCENTAGE \\
\hline Maternal age & & \\
\hline$<20 y r s$ & 5 & $1.1 \%$ \\
\hline $20-30 y r s$ & 298 & $88.16 \%$ \\
\hline$>30$ yrs & 35 & $10.6 \%$ \\
\hline & & \\
\hline Gravidity/ Parity & & \\
\hline Primi & 151 & $44.67 \%$ \\
\hline Multi & 158 & $46.74 \%$ \\
\hline Grandmulti & 29 & $8.57 \%$ \\
\hline & & \\
\hline Pregnancy status & & \\
\hline Antenatal & 112 & $33.13 \%$ \\
\hline Postnatal & 218 & $64.5 \%$ \\
\hline Postabortal & 8 & $2.36 \%$ \\
\hline & & \\
\hline Antenatal care & & \\
\hline Booked & 28 & $8 \%$ \\
\hline Unbooked & 310 & $92 \%$ \\
\hline & & \\
\hline Locality & & \\
\hline Rural & 116 & $34.31 \%$ \\
\hline Urban & 222 & $65.68 \%$ \\
\hline
\end{tabular}

Table II shows 298 (88.16\%) cases were of the age group of 20-30 yrs, which is the peak of reproductive age group. Maximum number of deaths were of multiparas i.e. 158(46.74\%), although primipara were also $151(44.67 \%)$ and grandmulti were $29(8.57 \%)$ cases. Deaths in post natal cases were 218(64.5\%), antenatal cases were $112(33.13 \%)$, and post abortal cases were $8(2.36 \%)$. Maximum maternal deaths were in unbooked cases i.e. $310(91 \%)$ patients as compared to $28(8 \%)$ booked cases. 252(74.55\%) were referred. 222(65.68\%) women who died belonged to rural area as compared to $116(34.31 \%)$ women of urban area.

Table III: - Other contributory factors

\begin{tabular}{|l|l|l|}
\hline DURATION FROM ADMISSION TO DEATH & NUMBER & PERCENTAGE \\
\hline$<6 \mathrm{hrs}$ & 137 & $40.5 \%$ \\
\hline $6-24 \mathrm{hrs}$ & 122 & $36.09 \%$ \\
\hline $24-72 \mathrm{hrs}$ & 53 & $15.6 \%$ \\
\hline$>72 \mathrm{hrs}$ & 26 & $7.6 \%$ \\
\hline & & \\
\hline ANTENATAL CARE PROVIDER & & \\
\hline None & 106 & $31.3 \%$ \\
\hline
\end{tabular}


ORIGINAL ARTICLE

\begin{tabular}{|l|l|l|}
\hline TBA & 69 & $20.4 \%$ \\
\hline ANM & 80 & $23.6 \%$ \\
\hline MO & 61 & $18.05 \%$ \\
\hline Specialist & 22 & $6.51 \%$ \\
\hline & & \\
\hline CONTRIBUTORY FACTORS & & \\
\hline Poverty & 277 & $82 \%$ \\
\hline Health care personnel problem & 250 & $74 \%$ \\
\hline Illiteracy & 209 & $61.8 \%$ \\
\hline Transport & 162 & $48 \%$ \\
\hline Lack of blood & 162 & $48 \%$ \\
\hline Multiple referrals & 78 & $23 \%$ \\
\hline
\end{tabular}

Table III shows that maximum number of patients died within $24 \mathrm{hrs}$ of admission. The graph shown below also depicts that maximum deaths occurred in $<6 \mathrm{hrs}$. This shows delayed referral from various centers and that patients were referred to our institute in moribund conditions.

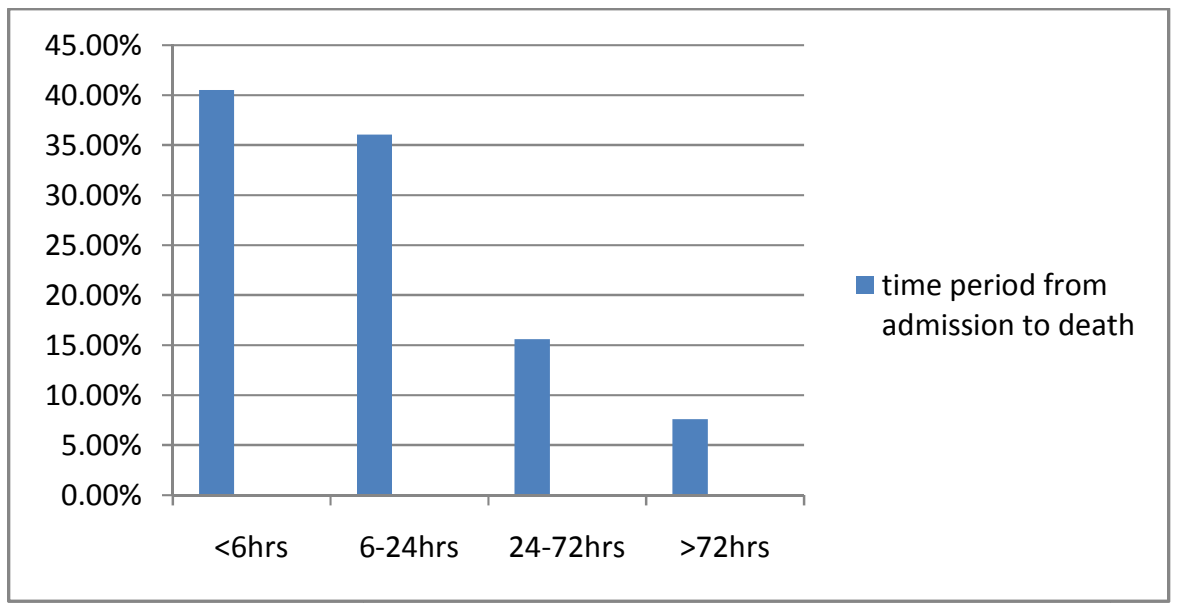

Table III also shows that $31.3 \%$ patients received no antenatal care, $20.4 \%$ by traditional birth attendants, and $23.6 \%$ by ANMs. $75.3 \%$ women received no proper antenatal care.

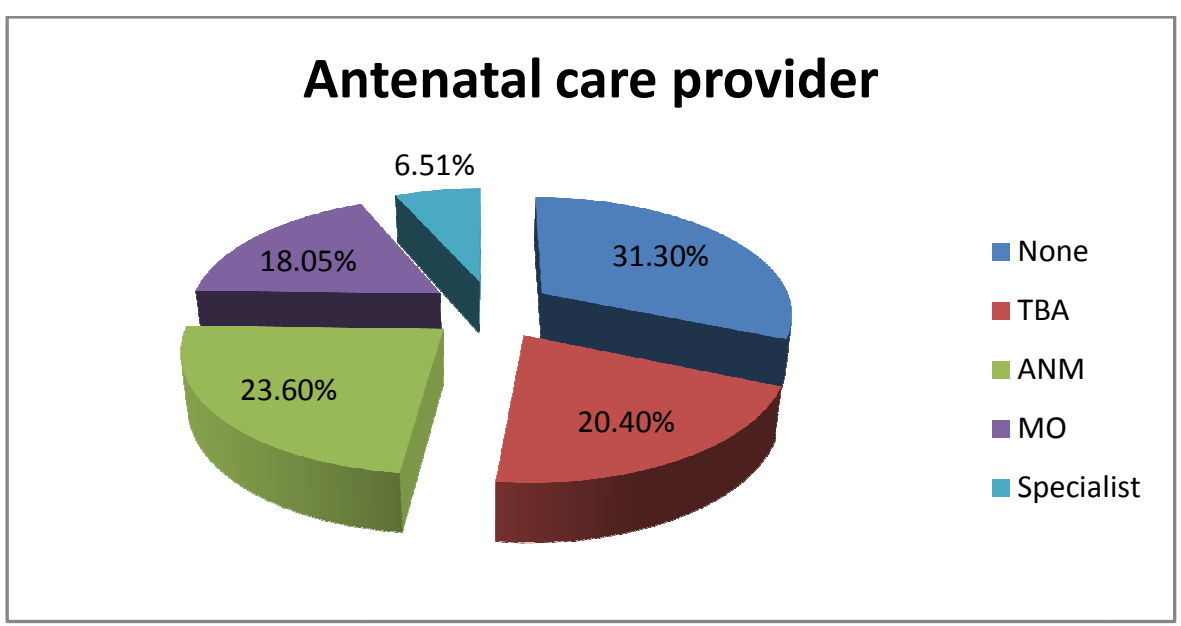

$82 \%$ women were of poor socioeconomic strata. $61.8 \%$ were illiterate and $23 \%$ had multiple referrals from different centers. 
Table IV: - Direct and Indirect causes of maternal death

\begin{tabular}{|l|l|l|}
\hline DIRECT CAUSES & NUMBER & PERCENTAGE \\
\hline Hypertension & 134 & $39.6 \%$ \\
\hline Hemorrhage & 64 & $18.9 \%$ \\
\hline Sepsis & 17 & $5.02 \%$ \\
\hline Rupture uterus/obstructed labor & 16 & $4.7 \%$ \\
\hline Unsafe abortion & 8 & $2.36 \%$ \\
\hline Pulmonary embolism & 6 & $1.77 \%$ \\
\hline Ectopic pregnancy & 5 & $1.47 \%$ \\
\hline Amniotic fluid embolism & 4 & $1.1 \%$ \\
\hline Inversion uterus & 2 & $0.5 \%$ \\
\hline INDIRECT CAUSES & NUMBER & PERCENTAGE \\
Anemia & & \\
\hline Malaria & 29 & $8.58 \%$ \\
\hline Hepatitis & 12 & $3.5 \%$ \\
\hline Heart disease & 9 & $2.66 \%$ \\
\hline Tuberculosis & 9 & $2.66 \%$ \\
\hline Meningitis & 8 & $2.47 \%$ \\
\hline ARF & 3 & $0.8 \%$ \\
\hline Dengue & 3 & $0.8 \%$ \\
\hline Diabetes & 2 & $0.59 \%$ \\
\hline Bronchial asthma & 2 & $0.59 \%$ \\
\hline Epilepsy & 2 & $0.59 \%$ \\
\hline & 2 & $0.59 \%$ \\
\hline & & \\
\hline
\end{tabular}

Table IV shows various causes of maternal deaths in our study. In our study $75.42 \%$ of deaths were due to direct causes. Hypertension is the leading cause of death $(39.6 \%)$, hemorrhage was found in $18.9 \%$, sepsis in $5.02 \%$, rupture uterus/obstructed labor in $4.7 \%$, unsafe abortion in $2.36 \%$ and rest of the direct causes constitute $4.84 \%$ of all maternal deaths.

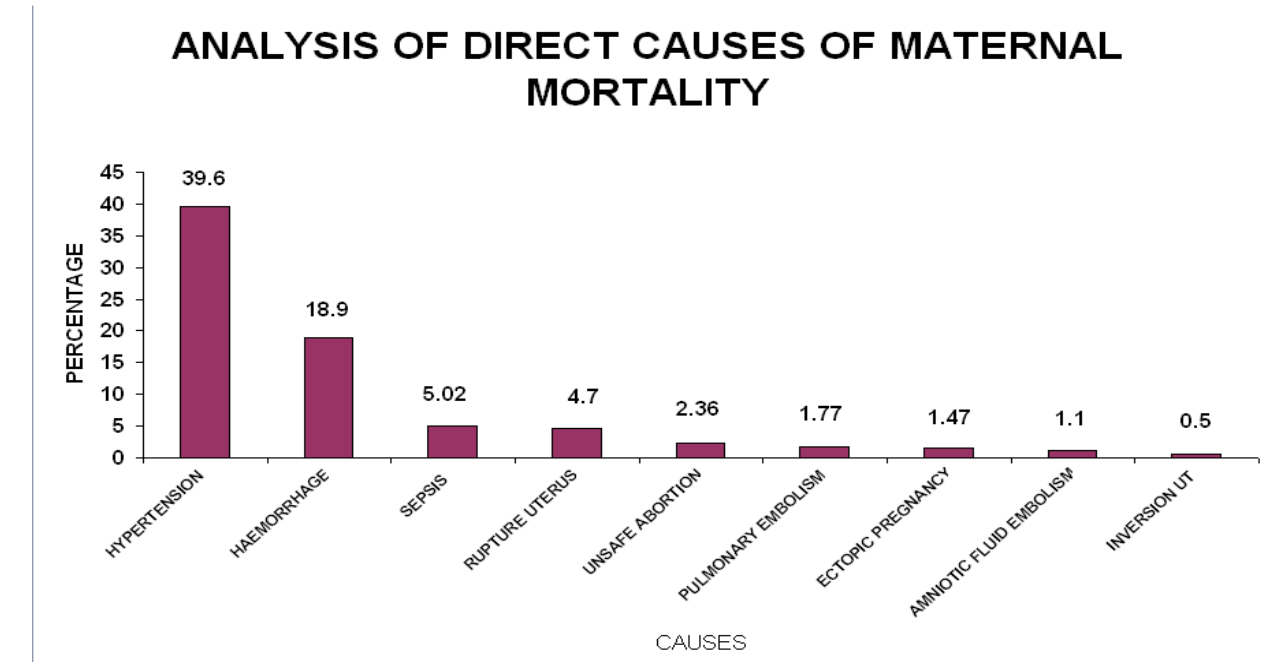


Indirect causes accounted for $24.58 \%$ of all maternal deaths. Major indirect causes that were found were anemia i.e. $8.58 \%$, malaria in $3.5 \%$, hepatitis in $2.66 \%$ and heart disease in $2.66 \%$.

\section{ANALYSIS OF INDIRECT CAUSES OF MATERNAL MORTALITY}

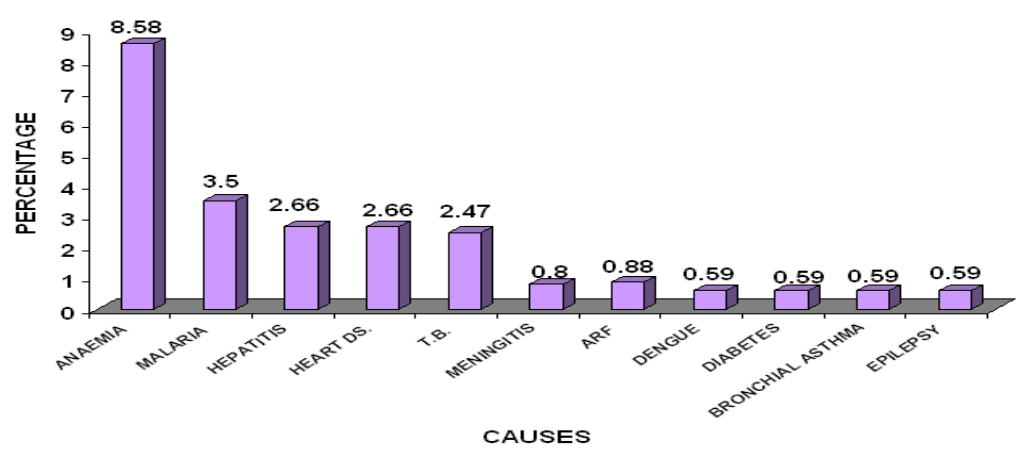

DISCUSSION: Today's status of maternal mortality and health issue shows a far greater disparity between developed and developing countries. As per 1993 statistics maternal mortality in developed country is 30 per 100,000 live births as compared to $450 / 100000$ live births in developing countries. Maternal mortality in India is not a chance event. It has its origins in many intertwined factors, starting with the social status, position of women, greatly affected by the economic resource and infrastructure of the country, and immediately dependent on accessibility and availability of skills, materials and facilities for family planning and maternity care. Reasons why woman die in pregnancy and child birth have many layers. Besides direct, indirect, and co-incidental causes, there are also logistic causes that is failure in the health care system, lack of transport, lack of manpower and apathy towards patient care. And behind these are all the social cultural and political factors which together determine the status of woman, their health, in 8000 for women in industrialized fertility and health seeking behaviour. To improve this scenario, the problem of the rural health is to be addressed both at the district, regional (micro) state and national (macro) level. [6]

Maternal mortality is a global tragedy. The maternal mortality rate has declined from 407/ 100,000 live births in 1999 to 212/ 100,000 live births according to SRS 2007-2009.[3]In Madhya Pradesh also it has declined from 498 to 310/ 100,000 live births. In the developing world as a whole, a woman has a 1 in 76 life time risk of maternal death, compared with a probability of just 1 countries [7]. It has to be understood that if India has to achieve the millennium development goals by 2015, we will have to work for the states like Madhya Pradesh, Bihar and Rajasthan currently having high rates of maternal mortality.

During the study period there were 43,683 live births and 338 cases of maternal deaths were found. MMR was found to be 773/100,000 live births. MMR was higher in our study, as our centre is a higher referral \& tertiary care centre. We received maximum referrals from rural areas. Most of the patients were referred in moribund condition after complications had occurred. Majority of patients were unbooked (92\%), belonging to rural area (65.6\%), mostly referred $(74.55 \%)$, illiterate $(61.8 \%)$. Majority of deaths occurred in post partum period $(64.5 \%)$. The most vulnerable time for maternal deaths is the postpartum period constituting $51-71 \%$ of all deaths. About $45 \%$ of postpartum maternal deaths occur during first $24 \mathrm{hrs}$ and > $2 / 3^{\text {rd }}$ during first week. Unfortunately the postpartum period is the most neglected period. In developing countries $65 \%$ women receive some form of antenatal care, $53 \%$ receive intranatal care and $30 \%$ have access to postpartum care. 
Table 5: Comparison with other studies

\begin{tabular}{|l|l|l|l|l|l|l|l|}
\hline author & $\begin{array}{l}\text { Place \& } \\
\text { year }\end{array}$ & direct & hemorrhage & hypertension & sepsis & anemia & $\mathrm{mmr}$ \\
\hline Patel et al [8] & 2001 & $62.8 \%$ & $31.9 \%$ & $13.7 \%$ & $20.9 \%$ & $17.4 \%$ & 3840 \\
\hline Khare et al[9] & 2002 & $83 \%$ & $66.7 \%$ & $13.3 \%$ & $3.3 \%$ & $53.3 \%$ & 2842.3 \\
\hline Singh et al [10] & 2003 & $66.5 \%$ & $16.1 \%$ & $24 \%$ & $17.9 \%$ & $15.8 \%$ & 3906 \\
\hline Kaur et al [11] & 2005 & $77.3 \%$ & $33 \%$ & $7.5 \%$ & $21.7 \%$ & $16 \%$ & 1470 \\
\hline $\begin{array}{l}\text { Vidhya et al } \\
{[12]}\end{array}$ & 2006 & $50 \%$ & $21 \%$ & $10.5 \%$ & $7.8 \%$ & $2.63 \%$ & 302 \\
\hline $\begin{array}{l}\text { Bhaskar et } \\
\text { al[13] }\end{array}$ & 2011 & $72.5 \%$ & $26.66 \%$ & $26.66 \%$ & $18.33 \%$ & $10 \%$ & 302.23 \\
\hline $\begin{array}{l}\text { PRESENT } \\
\text { STUDY }\end{array}$ & $\begin{array}{l}2007 \text { to } \\
2011\end{array}$ & $76.03 \%$ & $18.93 \%$ & $39.64 \%$ & $7.39 \%$ & $8.58 \%$ & 773 \\
\hline
\end{tabular}

Table 5 gives the maternal mortality rate in various studies conducted in India. MMR was found to be high in our study as most of the women were referred in terminal and irreversible condition from referral centers to our centre. In our study the MMR was 773. In the study of Kaur et al MMR was 1470 which is comparable to our study whereas Patel et al, Khare et al and Singh et al have reported even higher MMR in their studies. While Vidhya et al and Bhaskar et al have reported a very low MMR of 302 in their studies. Direct causes of maternal mortality account for $80 \%$ of all maternal deaths worldwide. In our study $76.03 \%$ of maternal deaths were due to direct causes which are consistent with other studies of Bhaskar et al (72.5\%), Patel et al (62.8\%), Khare et al (83\%), Singh et al (66.5\%), Kaur et al (77.3\%). Majority of direct causes of maternal mortality are preventable by high risk screening and proper antenatal, intranatal, emergency obstetric care. They are hemorrhage (25\%), infections / septicemia $(13 \%)$, eclampsia (12\%), obstructed labour (8\%), unsafe abortion (3\%), other direct causes (8\%). Indirect causes account for $20 \%$ of maternal deaths which includes causes like malaria, anemia, jaundice and other medical disorders which complicate pregnancy or are aggravated by it. In our study direct causes account for $76.03 \%$ of all maternal deaths, in which Hypertension tops the list (39.64\%) which is consistent with study of Singh et al, in contradiction to other studies in which hemorrhage was the most common cause of maternal deaths. All cases of hypertensive disorders were referred very late. About (62\%) were Eclampsia patients in the terminal stage. Hemorrhage was the second most common cause in which PPH accounts for $68 \%$ among hemorrhage cases. Sepsis accounted for $7.39 \%$ of all maternal deaths in our study. Among the indirect causes Anemia was the commonest cause which is also the leading indirect cause of maternal deaths in various studies. All of them were severely anemic with congestive cardiac failure. Malaria accounts for $3.5 \%$ of all cases. They came very late, all with complicated malaria. Madhya Pradesh accounts for $40 \%$ of all falciparum malaria cases in the country. All patients of hepatitis (2.66\%) came with deep jaundice \& Hepatic Encephalopathy. Majority of patients died within $24 \mathrm{hrs}$ of admission (about $76.5 \%$ ) which is directly related to late referrals from periphery.

CONCLUSION: The tragedy is that most of these maternal deaths are preventable. This has immense effect on the family especially on the child. When mother dies during delivery the child has 17 fold increase risk of death during the first six month (Sure Bergstrom 1994). Maternal death is not only due to medical causes but due to a number of other contributory factors. After 
this study it was concluded that hypertensive disorder of pregnancy has emerged as the leading cause of maternal deaths and can be prevented by proper antenatal care, screening and postnatal care. Early detection of high risk pregnancy and timely referral is very important. Referral card should be with important and adequate information. Basic and immediate management should be given as per protocol. Multiple referrals should be avoided. There should be a proper linkage between primary, secondary \& tertiary care centre. Other causes like Hemorrhage, sepsis, anemia should be taken in to account.

There are various ways to reduce maternal mortality like strengthening of referral services, written management protocols for obstetric emergencies in the hospital, refresher courses for the health care personnel, periodic audit of maternal death, social inequalities \& discrimination on grounds of gender should be removed. There is a need for cohesive \& integrated health care system. A mother should have an access to and PNC Services, access to skill birth attendant \& institutional deliveries, access to Emergency Obstetric Care (BEMOC+CEMOC), access to safe abortion services, easy transport \& blood transfusion facilities and access to information and services for family planning- too early, too frequent and too many.

\section{REFERENCES:}

1. International Statistical classification of diseases and Related Health Problems. Tenth Revision. Vol. 1: Tabular list. Vol.2: Instruction manual. Geneva: WHO 1992

2. WHO Maternal mortality in 2005: estimates developed by WHO, UNICEF

3. Special Bulletin on maternal mortality in India 2007-09: Sample Registration system, Office Registrar General, India; June 2011.

4. United Nations Millennium Declaration. Fifty fifth session of United Nations General Assembly. Newyork : United Nations; 18 September 2000 (general assembly document, No. A/ RES/55/2)

5. K. Park : Textbook of preventive and social medicine 20 $0^{\text {th }}$ edition; 480: 2009

6. Dr. D. K. Dutta, Reproduction \& Child health Care, FOGSI Publication,2008

7. UNICEF (2009), The State of World's Children 2009

8. Patel DA, Gangopadhyay S., Vaishnav SB et al. Maternal Mortality at Karamsad - The only Rural Medical College in Gujarat J Obstet Gynecol India. 2001; 51:63-6

9. Khare S, Singh KN, Kulkar S. Maternal mortality in Jabalpur Medical College (a 15 year study). J Obst Gynecol Ind 2002; 52(4): 51-54.

10. Singh R, Sinha N. Pattern of maternal mortality in a tertiary care hospital of Patna, Bihar. Ind J Community Med 2009; 34(1):73-74

11. Kaur D, Kaur V, Yuel VI. Alarmingly high maternal mortality in 21st century. JK Science 2007; 9(3):123-126.

12. Vidyadhar B. Bangal, Purushottam A. Giri, Ruchika Garg maternal Mortality at a tertiary care teaching hospital of Rural India; A Retrospective study : Int J Biol Med Res. 2011; 2(4): $1043-1046$.

13. Murthy BK, Murthy MB, Prabhu PM. Maternal Mortality in a tertiary care hospital: A 10year review. Int J Prev Med 2013; 4: 105-9. 